\title{
Outcomes of Endobronchial Valve Treatment Based on the Precise Criteria of an Endobronchial Catheter for Detection of Collateral Ventilation under Spontaneous Breathing
}

\author{
Dominik Herzog $^{a} \quad$ Christian Thomsen $^{a} \quad$ Alexander Poellinger ${ }^{b}$ \\ Felix Doellinger $^{b}$ Nils Schreiter ${ }^{c}$ Vera Froeling ${ }^{b}$ Dirk Schuermann ${ }^{a}$ \\ Bettina Temmesfeld-Wollbruck ${ }^{a}$ Stefan Hippenstiel ${ }^{a}$ Norbert Suttorp $^{a}$ \\ Ralf-Harto Huebner ${ }^{\mathrm{a}}$ \\ ${ }^{a}$ Department of Internal Medicine/Infectious Diseases and Respiratory Medicine, ${ }^{b}$ Institute of Radiology, and \\ ${ }^{C}$ Institute of Nuclear Medicine, Charité - Universitätsmedizin Berlin, Berlin, Germany
}

\section{Key Words}

Collateral ventilation · Interlobar fissures · Endobronchial valve treatment

\begin{abstract}
Background: Endoscopic lung volume reduction with valves is a valid therapeutic option for COPD patients with severe emphysema. The exclusion of interlobar collateral ventilation (CV) is an important predictor of clinical success. Objectives: Recently, a catheter-based endobronchial in vivo measurement system (Chartis, Pulmonx, USA) has become routine in the clinical evaluation of $\mathrm{CV}$ status in target lobes, but the criteria for phenotyping CV by Chartis evaluation have not yet been defined. We asked the questions, how many phenotypes can be identified using Chartis, what are the exact criteria to distinguish them, and how do the Chartis phenotypes respond to valve insertion? Methods: In a retrospective study, 406 Chartis assessments of 166 patients with severe COPD were analyzed. Four Chartis phenotypes, CV positive (CV+), CV negative (CV-), low flow (LF) and low plateau were identified. Fifty-two patients without CV were treated with valves and followed for 3 months. Results: The
\end{abstract}

Chartis phenotypes were discriminated with respect to decline in expiratory peak flow, increase in resistance index and change in total exhaled volume after 1, 2, 3, 4 and 5 min of measurement time ( $p<0.0001$, ANOVA), and the cutoff criteria were defined accordingly. To examine the application of these phenotyping criteria, students applied them to 100 Chartis assessments, and they demonstrated almost perfect inter- and intraobserver agreements ( $\mathrm{k}>0.9$ ). Compared to baseline, CV- and LF patients with ipsilateral CV- lobe showed an improvement in $\mathrm{FEV}_{1}(p<0.05)$, vital capacity $(p<0.05)$ and target lobe volume reduction $(p<0.005)$ after valve insertion. Conclusion: This study describes the most prevalent Chartis phenotypes.

(c) 2015 S. Karger AG, Basel

\section{Introduction}

Endoscopic lung volume reduction (ELVR) with valves has been shown to improve lung function, quality of life and exercise capacity and to reduce chest wall asynchrony in a subset of COPD patients with severe lung emphysema [1-7]. The most emphysematous regions of

\section{KARGER}

E-Mail karger@karger.com

www.karger.com/res (c) 2015 S. Karger AG, Basel

0025-7931/15/0911-0069\$39.50/0 
the lung are targeted for valve treatment while preserving the less diseased functional regions [8]. Recent studies have demonstrated that patients without collateral ventilation $(\mathrm{CV}-)$ have significantly greater clinical benefits following ELVR than patients with $\mathrm{CV}(\mathrm{CV}+)$ [1]. The phenomenon of $\mathrm{CV}$ is defined as the ventilation of lobes through passages or channels that bypass the normal airways [9-17].

It has become clinical routine to assess interlobar $\mathrm{CV}$ in target lobes prior to valve insertion, mainly by two methods, first, by the analysis of fissure integrity from a high-resolution CT scan [18-21], and second, by an endobronchial, in vivo measurement using the Chartis system (Pulmonx Inc., USA) [1]. Morrell et al. [22] suggested as early as 1994 that a balloon catheter occluding a lobe or a segment could be delivered via a bronchoscope using Heliox to measure CV.

In 2009, the Chartis system was introduced into clinical practice [23]. It includes an external console and a catheter that is inserted into the bronchus of the target lobe via the working channel of the bronchoscope. An inflatable balloon is located at the tip of the Chartis catheter, designed to seal the airway, while sensors located in the external console measure the expiratory and inspiratory flow and pressure. Little is known about Chartis phenotypes or the criteria distinguishing them. Recently, a resistance index $(\mathrm{Rndx})>10 \mathrm{~cm} \mathrm{H}_{2} \mathrm{O} \times \mathrm{s} / \mathrm{ml}$ was proposed as a criterion of high collateral resistance and typical of $\mathrm{CV}$-, but these data were based only on a very small number of patients [24]. Another study defined a CV-phenotype as a gradual decrease in airflow, and a $\mathrm{CV}+$ phenotype as a continuous flow, but these lacked clean cut-off criteria and information on measurement times. In this context, we asked the questions: how many phenotypes could be identified using Chartis, what are the exact criteria of the variables used to distinguish these phenotypes and how do patients with these phenotypes respond to valve insertion?

\section{Methods}

\section{Patients}

Between August 2010 and May 2015, 166 severe COPD patients were assessed prior to ELVR by the Chartis console (Pulmonx) at our hospital, and the assessments were retrospectively analyzed. The anonymous analysis of the Chartis assessments was approved by the local ethics committee with the study goals to specify how many phenotypes could be identified using Chartis and what the exact criteria are of the variables used to distinguish these Chartis phenotypes (EA1/064/12).
Initially, the patients had an ambulant visit to the outpatient clinic to be evaluated for ELVR treatment. At this visit, the patients had a physical examination, optimizations for COPD medication and oxygen therapy, pulmonary function and diffusion tests (Weinmann, Germany), a six-minute walk test, the St. George Respiratory Questionnaire and blood gas analysis that included testing the carboxyhemoglobin levels. The patients were instructed to exhaust all conservative treatment options such as a cure with optimization of physiotherapy before considering ELVR with valves.

From December 2010 to February 2015, 52 patients without $\mathrm{CV}$ as determined by the new Chartis criteria were treated with endobronchial valves. The clinical outcomes of these patients following valve insertion were evaluated with the approval of the local ethics committee (EA1/136/13) with the aim to analyze how the different Chartis phenotypes respond to valve treatment.

The inclusion criteria for ELVR treatment were patients over 40 years of age diagnosed with severe lung emphysema, GOLD stage III or IV, and a nonsmoker status verified by carboxyhemoglobin levels below $2.0 \%$. The exclusion criteria were a forced expiratory volume in $1 \mathrm{~s}\left(\mathrm{FEV}_{1}\right)$ either below $15 \%$ of the predicted value (pred.) or above $45 \%$ pred., a residual volume (RV) below $150 \%$ pred., a total lung capacity below $100 \%$, or major comorbidities, such as significant pulmonary hypertension or unstable cardiac conditions.

\section{Chartis Assessment}

The CV was assessed with the Chartis console in an ambulant bronchoscopic setting. As a premedication, patients were given 50 $\mathrm{mg}$ pethidine to reduce coughing during measurement. To minimize bronchial secretions, $0.5 \mathrm{mg}$ atropine was administered if the pulse rate fell below 100 beats/min.

The Chartis assessments were taken under spontaneous breathing. For the bronchoscopic sedation, 2.5-5.0 mg midazolam and $10-20 \mathrm{mg}$ propofol boli (up to $400 \mathrm{mg}$ maximum) were used. All patients were intubated with a 7.5 endotracheal tube with a separate oxygen tube (Bronchoflex, Rüsch, Germany) to keep the central airways open and to ease the insertion and removal of the bronchoscope. The patients received 2-6 liters/min oxygen, continuously assessed during bronchoscopy according to oxygen saturation.

The Chartis system includes a catheter with an inflatable balloon at its tip and an external console to record the measurements. After instillation of 10-15 $\mathrm{ml} \mathrm{1 \%} \mathrm{lidocaine} \mathrm{into} \mathrm{the} \mathrm{tracheobron-}$ chial tree and target lobes for local anesthesia, the Chartis catheter was inserted via the working channel of the bronchoscope (PentaxEurope, Hamburg) and placed in front of the ostium of the target lobe's main bronchus. The balloon was then inflated until the bronchus was completely sealed. The tip of the catheter was placed in a manner that allowed airflow from all segments of the target lobe to reach the catheter tip. A complete sealing of the target lobe by the balloon was maintained throughout the measurement period, including the 10 -second pre- and postassessment periods.

Chartis assessments were included in this study only if they had detectable expiratory flows (ExpF) during the pre- and postassessment periods. ExpF, inspiratory pressure, total exhaled volume (TVol) and the ratio of inspiratory pressure to ExpF, termed resistance (Rndx), were recorded by the Chartis console in real time (Rrt) and visually shown on the display (fig. 1). The Rndx is the average of the Rrt over the course of the measurement period. The measurement time lasted longer than $4 \mathrm{~min}$, stopping earlier only 
Fig. 1. Chartis phenotypes. The left columns represent the ExpF curve (orange) and the inspiratory pressure (blue), and the right columns represent the resistance curves in Rrt (green) and cumulative per time (blue; colors refer to the online version only). a No decrease in ExpF and no increase in Rndx. $\mathbf{b}$ Decrease in ExpF and corresponding increase in Rndx. c Sudden decrease in ExpF to zero and abrupt increase in Rndx. d Decrease in ExpF reaching a plateau with no corresponding increase in Rndx.

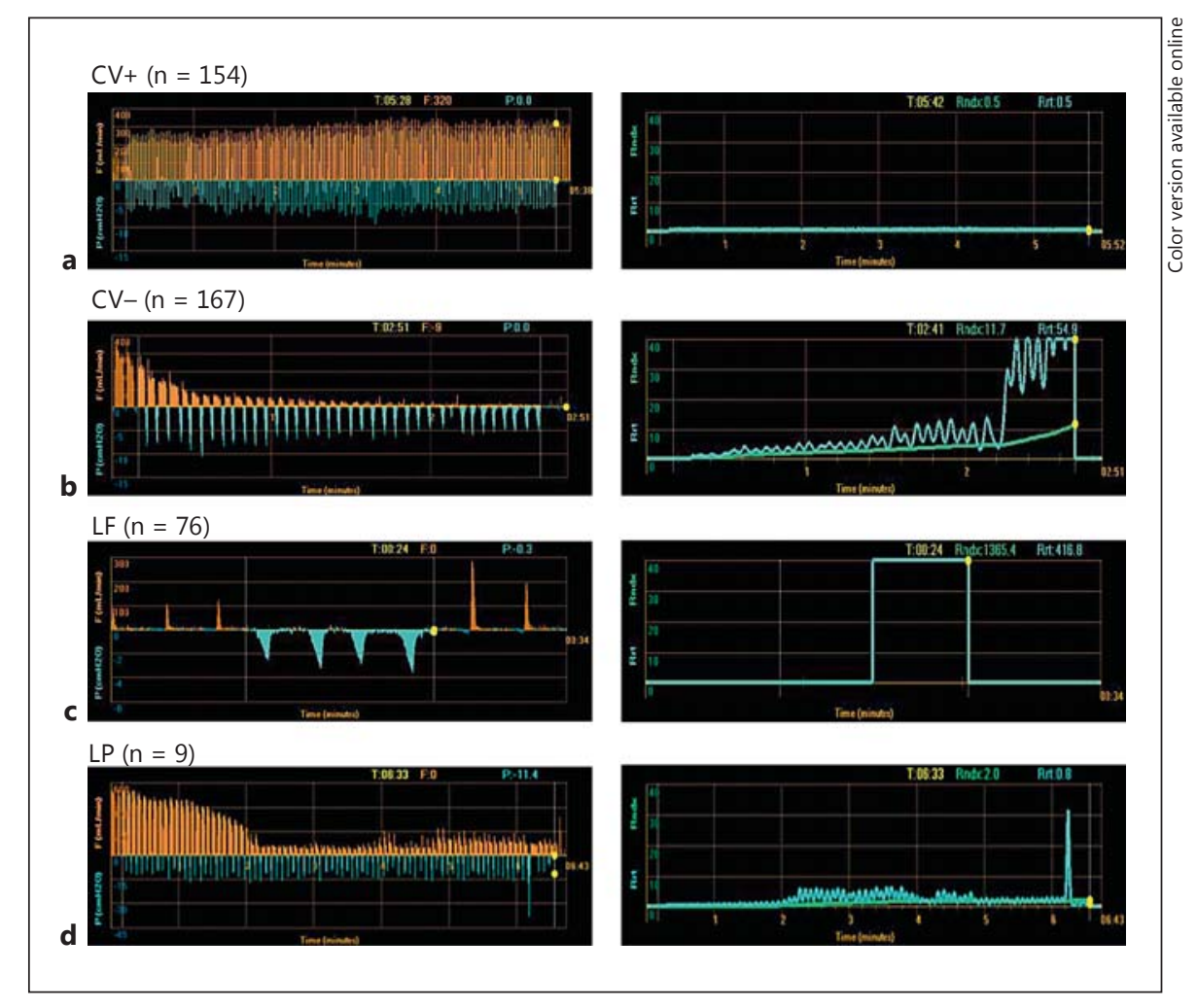

if there was an increase in the Rndx greater than $10 \mathrm{~cm} \mathrm{H}_{2} \mathrm{O} \times \mathrm{s} /$ $\mathrm{ml}$, as recently suggested [24], or if the ExpF showed a trend towards zero, both criteria applying to the $\mathrm{CV}$ - phenotype. As an assessment algorithm, the primary and secondary target lobes were measured in sequence. If the assessments were inconclusive with regard to the presence or absence of $\mathrm{CV}$, such as with the low flow (LF) or some low plateau (LP) phenotypes, the corresponding ipsilateral lobe was measured. In the case of significant artifacts during assessments preventing a conclusive phenotype, the Chartis assessment was repeated. If the LF phenotype turned into a CV+ or CV-phenotype in the second assessment, only the second assessment was included into the study. If several assessments were available for one lobe, only the assessment with the best quality was used. The middle lobe (ML) was excluded from all analyses in this study because it has too little volume to be a primary target for valve therapy.

\section{Definition of Chartis Criteria by Visual Assessment and}

Software-Based Analyses

All Chartis assessments were visually categorized into the Chartis phenotypes. The Chartis phenotypes were analyzed by software (LabView, National Instruments, USA) with respect to the parameters which are displayed on the Chartis console in realtime: expiratory peak flow (ExpF, $\mathrm{ml} / \mathrm{min}$ ), Rndx (unit: $\mathrm{cm} \mathrm{H}_{2} \mathrm{O} \times$ $\mathrm{s} / \mathrm{ml}$ ) and TVol (ml), after 1, 2, 3, 4 and 5 min of Chartis measurement time. The ExpF corresponds to the percentage change in ExpF peaks relative to the last ExpF peak before the start of the measurement. The Rndx was calculated by the Chartis console. The Chartis cutoff criteria were defined from these values.

\section{Validation of Chartis Criteria}

To validate the Chartis criteria obtained from the visual and software analyses of the 304 available measurements, 100 consecutive Chartis assessments taken between 07/2011 and 05/2012 were randomly chosen, printed and numbered in a blinded fashion. Seven readers (4th-year medical students) were asked to phenotype these 100 assessments using the new criteria. They were provided with the description of each phenotype (online suppl. table 1; see www.karger.com/doi/10.1159/000442886 for all online suppl. material) and with sample photographs taken by the authors (fig. 1) to assist in the evaluation. To assess the intraobserver agreement, all students made a second evaluation of the same 100 Chartis assessments in reverse order on the day following the first evaluation. The authors most familiar with Chartis assessments determined the correct phenotype of all the evaluations.

\section{Endobronchial Valve Treatment}

The patients were hospitalized 1 day prior to ELVR valve treatment and examined for stable condition. The bronchoscopic setting including premedication and the sedation protocol were the same as in the bronchoscopic setting for the Chartis assessments. Zephyr valves (Pulmonx) in three sizes (4.0, 4.0-LP and 5.5) were used. For complete occlusion, valves were inserted into lobar, segmental or subsegmental bronchi according to the patient's individual lung anatomy. Radiologists and pneumologists defined the target lobe for treatment by the absence of CV and the highest emphysema distribution and/or lung destruction. After ELVR, all patients were hospitalized and discharged at the earliest 4 days after valve implantation if they were in stable conditions. 
Table 1. Baseline characteristics of patients

\begin{tabular}{lc}
\hline Patients & 166 \\
Sex & \\
Male & 102 \\
Female & 64 \\
Age, years & $66.4 \pm 1$ \\
BMI & $24.7 \pm 1$ \\
Smoking history, pack-years & $45.2 \pm 2$ \\
Pulmonary function test & \\
FEV, \% pred. & $26.7 \pm 1$ \\
VC, \% pred. & $64.2 \pm 1$ \\
RV, \% pred. & $218.6 \pm 5$ \\
TLC, \% pred. & $122.2 \pm 2$ \\
DLCO, \% pred. & $26.8 \pm 2$ \\
6MWT, m & $220.2 \pm 12$ \\
SGRQ & $66.2 \pm 2$ \\
Patients treated with valves & 52 \\
Chartis CV+/CV-/LF/LP phenotype & $0 / 36 / 16 / 0$ \\
Valves per patient & $3.8 \pm 1$ \\
Treatment site & \\
$\quad$ RUL & 7 \\
RLL & 6 \\
LUL & 15 \\
LLL & 24 \\
\hline
\end{tabular}

Data are presented as number or mean \pm standard error. $\mathrm{BMI}=$ Body mass index $; \mathrm{VC}=$ vital capacity; $\mathrm{RV}=$ residual volume; TLC = total lung capacity; DLCO = diffusion capacity of CO; $6 \mathrm{MWT}=$ six-minute walk test; SGRQ $=$ St. George's Respiratory Questionnaire; RLL = right lower lung; LLL = left lower lung.

Quantification of Computed Tomography

Computed tomography (CT) was performed before the Chartis assessment to quantify the lung emphysema in the lobes. Another CT was taken at follow-up to evaluate the target lobe volume reduction (TLVR). It was performed using the MeVisPULMO software (Fraunhofer MEVIS, Germany). A TLVR of $>350 \mathrm{ml}$ in the target lobe defined the significant cutoff criterion for lung volume reduction.

\section{Follow-Up}

At 3 months, patients underwent a physical examination, pulmonary function tests and CT scans analyzed with Pulmo3D to determine TLVR.

\section{Statistical Analyses}

The Chartis phenotypes were analyzed by one-way analysis of variance (ANOVA) with respect to TVol, ExpF and Rndx at 1, 2, 3,4 and $5 \mathrm{~min}$. The $\chi^{2}$ test and the Fisher's exact test for discrete variables were used for the statistical analysis of categorical variables. The ordinal variables were compared with the Mann-Whitney $U$ test. A p value $<0.05$ was considered statistically significant. Cohen's kappa was used to calculate the interobserver and intraobserver reliability of the Chartis criteria. The data are displayed as mean \pm standard deviation. SPSS (IBM, version 20) was used for the statistical analyses.

\section{Results}

A total of 451 Chartis assessments corresponding to 451 lobes from $166 \mathrm{COPD}$ patients ( $66 \pm 1$ years old, $\mathrm{FEV}_{1}$ $27 \pm 1 \%$ pred., RV $219 \pm 5 \%$ pred.) were analyzed. Fortyfive (45) assessments had to be excluded due to artifacts (examples of artifacts are shown in online suppl. fig. 1). The rate of measurement artifacts in our clinic decreased continuously from $20 \%$ in 2011 to $8 \%$ in 2015.406 Chartis assessments were conclusive and included for further analyses in this study. The baseline characteristics of the patients are shown in table 1. Based on visual and software analyses, four Chartis phenotypes were identified: $\mathrm{CV}+, \mathrm{CV}-$, LF and LP (fig. 1).

Out of the 406 analyzed lobes, 154 were $\mathrm{CV}+, 167$ $\mathrm{CV}-, 76 \mathrm{LF}$ and $9 \mathrm{LP}$. The phenotypes were assessed visually and by software over measurement periods of up to 5 min, with respect to $\operatorname{ExpF}$ (fig. 2a), Rndx (fig. 2b) and TVol (fig. 2c). In detail, $100 \%$ of the CV+ and LP phenotypes had a Chartis measurement duration greater than 4 min and $40 \%$ of CV+ and $100 \%$ of LP phenotypes had measurement durations greater than $5 \mathrm{~min}$. None of the $\mathrm{CV}+$ lobes had a decrease in ExpF below 50\% ( $\mathrm{p}=0.1$ vs. baseline). All CV-phenotypes showed a gradual decrease in ExpF below $50 \%$ within 4 min of measurement time ( $p<0.001$ vs. baseline) and below $20 \%$ within 5 minutes of measurement time ( $\mathrm{p}<0.001$ vs. baseline). LP showed a decrease in ExpF below 50\%, reaching a plateau above $20 \%$ ( $\mathrm{p}<0.0001$ vs. baseline). After 3 min of measurement time, $79 \%$ of $\mathrm{CV}+$ phenotypes showed an ExpF greater than $80 \%$, while all CV- and LP phenotypes had an ExpF considerably lower than $80 \%$. LF demonstrated a sudden decrease of ExpF to zero within the first 30 s of measurement time ( $\mathrm{p}<0.0001$ vs. baseline). ExpF differs significantly between all phenotypes at all time points $(\mathrm{p}<$ 0.0001 , ANOVA).

With regard to the Rndx, all CV+ and LP assessments remained below $3 \mathrm{~cm} \mathrm{H} \mathrm{H}_{2} \mathrm{O} \times \mathrm{s} / \mathrm{ml}$ during measurement times up to $5 \mathrm{~min}$ and were characterized by the same curve pattern ( $p=0.9$, ANOVA). In contrast, all CVphenotypes demonstrated an increase of the Rndx greater than $3 \mathrm{~cm} \mathrm{H}_{2} \mathrm{O} \times \mathrm{s} / \mathrm{ml}(\mathrm{p}<0.0001$ vs. baseline). The cutoff criterion of $3 \mathrm{~cm} \mathrm{H} \mathrm{H}_{2} \mathrm{O} \times \mathrm{s} / \mathrm{ml}$ was reached in $25 \%$ of the assessments in less than $1 \mathrm{~min}$, in $64 \%$ less than $2 \mathrm{~min}$, in $83 \%$ less than $3 \mathrm{~min}$, in $96 \%$ less than $4 \mathrm{~min}$, and all of the $\mathrm{CV}$ - cases exceeded $3 \mathrm{~cm} \mathrm{H}_{2} \mathrm{O} \times \mathrm{s} / \mathrm{ml}$ within $5 \mathrm{~min}$. The LF assessments were characterized by a sharp increase in the Rndx of over $100 \mathrm{~cm} \mathrm{H}_{2} \mathrm{O} \times \mathrm{s} / \mathrm{ml}$, already within the first $30 \mathrm{~s}$ of measurement time ( $\mathrm{p}<0.0001 \mathrm{vs.}$ baseline). 


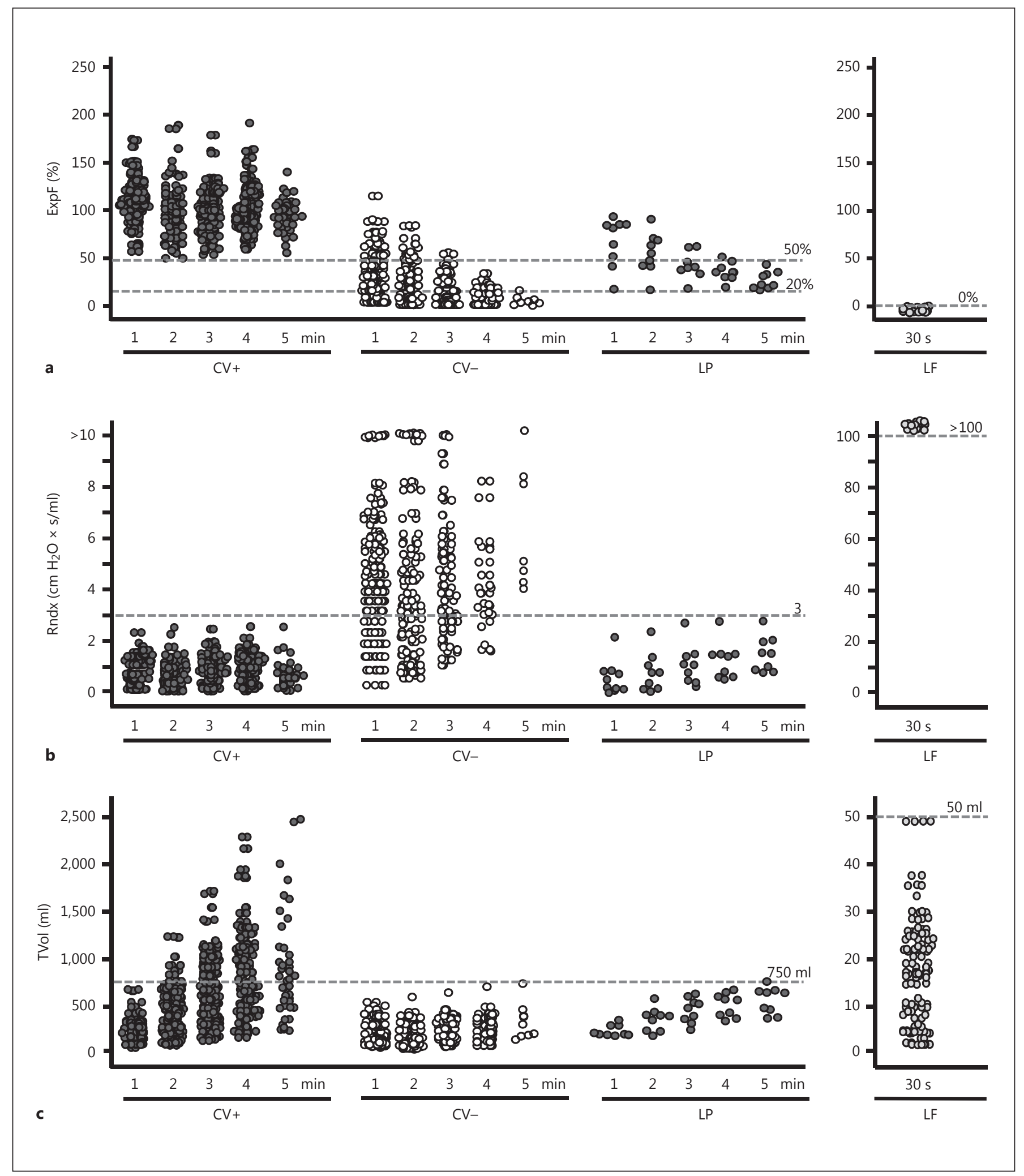

Fig. 2. Definition of Chartis criteria. $\operatorname{ExpF}(\mathbf{a}), \operatorname{Rndx}(\mathbf{b})$ and TVol (c) were analyzed for each Chartis phenotype after 1, 2, 3, 4 and $5 \mathrm{~min}$. Each circle represents one Chartis assessment per lobe per time point. Dashed grey lines represent the cutoff criteria. 


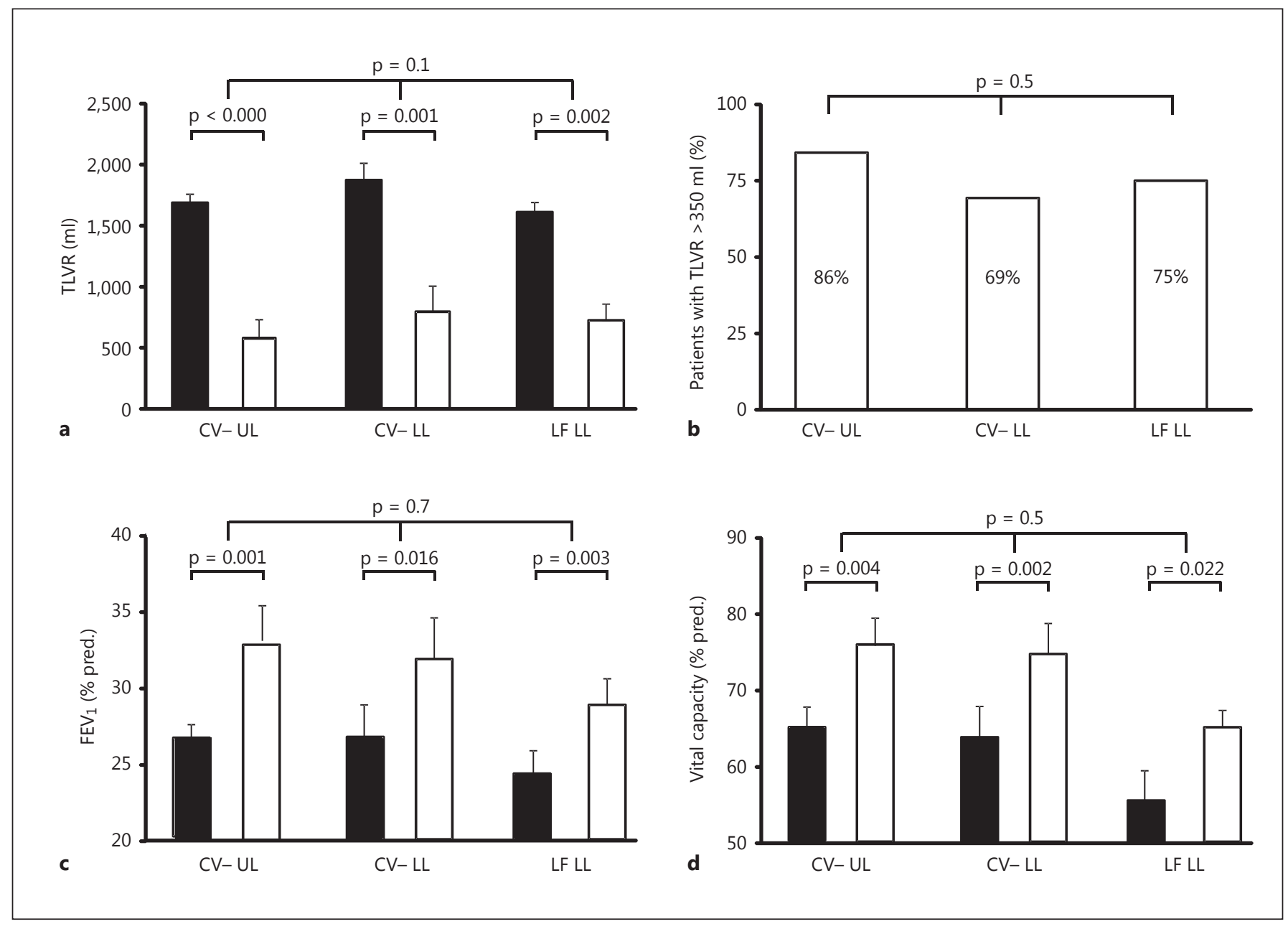

Fig. 3. Outcomes after ELVR. The patients were followed for 3 months. The baseline values (black bars) were compared with the 3-month control values (white bars) in valve-treated patients with CV- UL, CV- LL and LF LL. a TLVR. b Patients with TLVR $>350 \mathrm{ml}$. c FEV 1 . d Vital capacity. Data are presented as mean \pm standard error.

TVol was evaluated to distinguish the Chartis phenotypes further (fig. 2c). CV+ demonstrated an increase in TVol greater than in CV-, LF and LP ( $p<0.001$ after 4 min; ANOVA). At $4 \mathrm{~min}, 77 \%$ of $\mathrm{CV}+$ assessments exceeded $500 \mathrm{ml}$ and $89 \%$ at $5 \mathrm{~min}$, while almost all CV-assessments (99\%) had a TVol below $500 \mathrm{ml}$. There was one $\mathrm{CV}$ - outlying assessment in left upper lobe (LUL) with a TVol greater than $500 \mathrm{ml}$ already after $2 \mathrm{~min}$ of measurement time, in particular due to deep ventilation at the beginning of the assessment. In this case, at the end of the measurement period, at 5:28 min, the ExpF reached zero and the TVol was $737 \mathrm{ml}$. The TVol was greater in LP than in CV- ( $p=0.002$ at $4 \mathrm{~min})$. Only LF demonstrated a TVol less than $50 \mathrm{ml}$.
To validate the Chartis criteria, 7 readers (4th-year medical students) assessed $33 \mathrm{CV}+, 36 \mathrm{CV}-, 16 \mathrm{LF}, 4 \mathrm{LP}$ and 11 artifact assessments out of 100 randomly chosen Chartis assessments. The readers showed an almost perfect intraobserver $(\kappa>0.9)$ and interobserver agreement ( $\kappa>0.9$; online suppl. table 2 ).

Fifty-two patients were retrospectively subdivided into three subgroups for the analysis of the clinical outcomes. At 3 months, 18 of $21 \mathrm{CV}$ - upper lobes (UL), 9 of 13 CV-lower lobes (LL) and 9 of 12 LF LL received CT quantification and had a significant TLVR of more than $350 \mathrm{ml}$ as assessed by CT scans (fig. 3a) with a mean TLVR of $1,112.9 \pm 134 \mathrm{ml}$ in CV- UL, $1,074.0 \pm 223 \mathrm{ml}$ in CVLL and $725.1 \pm 133 \mathrm{ml}$ in LF LL (fig. 3b) compared to 
baseline. There were also significant mean improvements in $\mathrm{FEV}_{1}: 26.9 \pm 6 \%$ in $22 \mathrm{CV}-\mathrm{UL}, 21.7 \pm 7 \%$ in $14 \mathrm{CV}-$ LL and $20.3 \pm 6 \%$ in 16 LF LL (fig. 3c), and in vital capacity: $16.5 \pm 4 \%$ in $22 \mathrm{CV}-\mathrm{UL}, 19.5 \% \pm 5$ in $14 \mathrm{CV}-\mathrm{LL}$ and $29.5 \%$ in 16 LF LL (fig. 3d) compared to baseline.

\section{Discussion}

Chartis represents a real-time measurement of dynamic changes in the collaterals of COPD lungs. Although there is still no gold standard for the detection of CV, visual analysis of fissure integrity from CT scans and quantitative CT (e.g. VIDA diagnostics ${ }^{\circledR}$ ) are potential alternatives to Chartis, and eventually a combination of the methods is needed to select the most appropriate candidates for ELVR. A recent study showed that pneumologists and radiologists agree at most moderately in visual fissure analysis and concluded that the visual analysis might require experienced chest radiologists [18]. Quantitative CT is a potential alternative to Chartis and has recently shown comparable results for selecting appropriate patients for ELVR $[25,26]$. The Chartis measurement is known to be complicated particularly in patients with difficult anatomy, coughing or when mucous clogs the tip of the Chartis catheter. In our data set, about $90 \%$ of the assessments were conclusive, and in our clinic, the number of inconsistent measurements due to artifacts has decreased with the increasing experience of the bronchoscopists. The rate of inconclusive assessments decreased from 20\% in 2011 to $8 \%$ in 2015 . Inconclusive assessments consisted of the Chartis tip touching the bronchial wall, coughing artifacts, secret occlusion of the tip or when the patient was exhaling on exertion during the assessment (see examples in online suppl. fig. 1). In this context, premedication with drugs such as atropine or pethidine helped in our hands to reduce endobronchial secretion and coughing; nevertheless, it is mandatory that the contraindications and side effects of these drugs be considered. Interestingly, some assessments also showed a sudden drop in flow accompanied by a sharp increase in the Rndx (example in online suppl. fig. 1F) mainly in CV-phenotype lobes at the end of the assessment, probably due to a dynamic collapse similar to that in the LF phenotype.

Only the CV-phenotype has been described to benefit from ELVR with valves. Various studies have shown no significant improvement in CV+ patient groups, and we did not treat this phenotype with valves $[1,2]$. Therefore, criteria are urgently required for a reliable discrimination of the Chartis CV- and CV+ phenotypes.
This is the first analysis providing adequate cutoff criteria for phenotyping Chartis assessments of CV. CV+ was characterized by no significant decrease in ExpF below $50 \%$ and no significant increase in the Rndx above $3 \mathrm{~cm} \mathrm{H} \mathrm{H}_{2} \mathrm{O} \times \mathrm{s} / \mathrm{ml}$, within the $5 \mathrm{~min}$ of measurement time. In many $\mathrm{CV}+$ lobes, there was a continuous air supply from the adjacent lobes through collaterals into the target lobe, which explained the high TVol of more than $750 \mathrm{ml}$ during the measurement period. After $3 \mathrm{~min}, 79 \%$ of $\mathrm{CV}+$ had an ExpF over 80\%, while all of CV- and LP demonstrated an ExpF below 80\%, suggesting this cutoff criterion to be helpful in phenotyping a majority of $\mathrm{CV}+$ assessments at only 3 min of measurement time.

$\mathrm{CV}$ - was characterized by a gradual decline in ExpF below $20 \%$ and a corresponding increase in the Rndx of more than $3 \mathrm{~cm} \mathrm{H} \mathrm{H}_{2} \mathrm{O} \times \mathrm{s} / \mathrm{ml}$. TVol remained below 750 $\mathrm{ml}$ during the measurement period because $\mathrm{CV}$ - lobes are fully occluded with no other air supply from the other lobes during the Chartis assessment. As a consequence, $\mathrm{CV}$ - demonstrated shorter measurement times than did $\mathrm{CV}+$ and LP lobes.

LF became evident quickly, following only a few breaths, such that measurement times never exceeded $30 \mathrm{~s}$ (fig. 2). LF showed an abrupt decrease in ExpF towards zero and a corresponding sharp increase in the $\mathrm{Rndx}$ of more than $100 \mathrm{~cm} \mathrm{H}_{2} \mathrm{O} \times \mathrm{s} / \mathrm{ml}$. There was almost no flow detected in TVol, such that synonymously LF might also be termed 'no flow'. There are currently several hypotheses about the causes of LF: A possible explanation is the presence of CV in the LF Chartis-measured lobe. According to this hypothesis, the presence of collateral channels results in the exhaled air finding alternate paths of lower resistance to flow out, which is perceived as an airway with LF by the Chartis console. Since we have assessed many ipsilateral lobes as $\mathrm{CV}$-, we think the presence of CV is an unlikely explanation for all LF. Another hypothesis suggests distal airway collapse due to inherent properties of the airway or due to the Chartis catheter itself limiting the lumen of the airways. A blockage of the catheter by secretions or the apposition of the catheter against the airway is also possible [27, 28]. We repeated the LF assessments in a large cohort being careful to exclude measurement artifacts and the majority of assessments showed the LF pattern again.

LF was almost always seen in LL, and thus almost never in UL, suggesting that the parenchyma in LL is more vulnerable to collapsing. As a sign of collapsed airways, TVol was less than $50 \mathrm{ml}$, another typical pattern of LF. LF does not allow the conclusions regarding the presence of collateral channels in this specific lobe that fissure analysis 


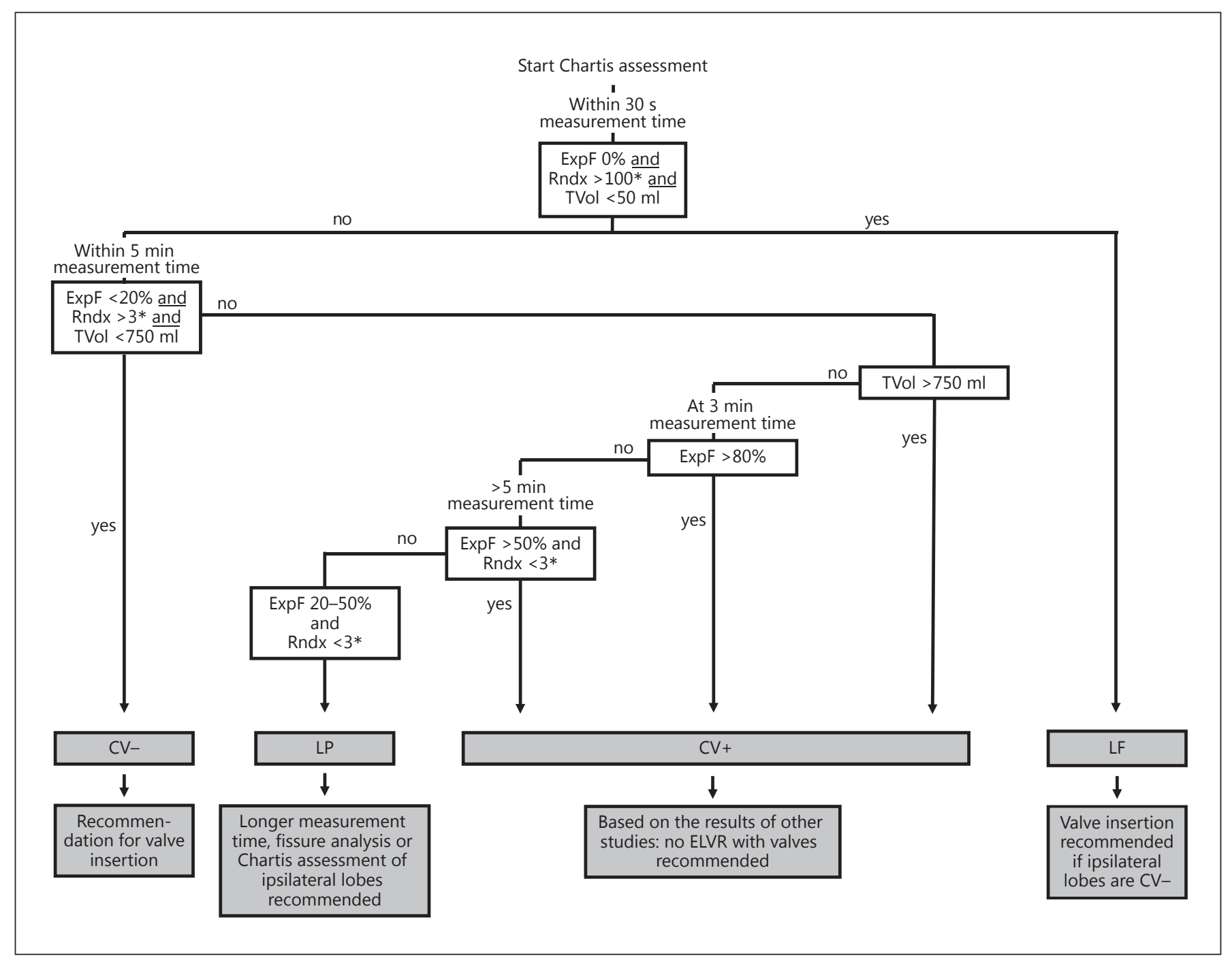

Fig. 4. Diagnostic algorithms for Chartis phenotyping with respect to ExpF, Rndx and TVol and therapeutic recommendations. Asterisks indicate $\mathrm{cm} \mathrm{H}_{2} \mathrm{O} \times \mathrm{s} / \mathrm{ml}$.

by CT scan does. A possible option to detect the presence or absence of CV in LF LL in the right lung might be the occlusion of the right middle lobe by another Chartis balloon and the simultaneous Chartis measurement of right upper lobe (RUL). Another theoretical option for better characterization of $\mathrm{CV}$ might include the application of a reverse Chartis flow into the lung resulting in an increased pressure in $\mathrm{CV}$ - lobes, whereas in $\mathrm{CV}+$ lobes the pressure would remain unchanged. A Chartis assessment of the ipsilateral UL is recommended prior to valve treatment to decide whether the patient can be treated with valves (ipsilateral lobes $\mathrm{CV}_{-}$) or not (ipsilateral lobes $\mathrm{CV}+$ ). We successfully applied this algorithm in treating LF patients.
LP is a newly identified phenotype that could not be assigned to either $\mathrm{CV}-$ or $\mathrm{CV}+$. It is characterized by a $\mathrm{CV}$ - like pattern at the beginning of the measurement period, which is followed by a gradual decline in ExpF below 50\% that reaches a plateau in ExpF above 20\%. The $\mathrm{Rndx}$ remains lower than $3 \mathrm{~cm} \mathrm{H}_{2} \mathrm{O} \times \mathrm{s} / \mathrm{ml}$, resembling the $\mathrm{CV}+$ curve pattern during a measurement time of $5 \mathrm{~min}$, but which can be distinguished from a CV+ assessment by the decrease in ExpF below 50\%. LP might take an intermediate position between $\mathrm{CV}+$ and $\mathrm{CV}$ - phenotypes, and a measurement time of more than $5 \mathrm{~min}$ is recommended to evaluate whether the LP pattern converts into a $\mathrm{CV}$ - phenotype by a decrease in ExpF together with 
a corresponding increase in Rndx above 3 . The causes of LP are elusive, but the remaining ExpF during the measurement period may suggest the presence of micro-collaterals between the lobes. The exclusion of $\mathrm{CV}$ in the ipsilateral lobes and a fissure analysis are further options in deciding whether an LP lobe can be treated with valves or not.

The clinical outcomes were similar in the treated patients with CV- UL, CV- LL or LF LL phenotypes. The prognostic importance of LF was previously unknown $[27,28]$. The outcomes of this study suggest that patients with the LF phenotype can successfully be treated with valves after exclusion of CV in the ipsilateral UL. These treatment outcomes provide evidence that there was an efficient selection of our patients for ELVR as a result of using the precise Chartis criteria. An algorithm for Chartis assessments and recommendations with respect to ELVR with valves is shown in figure 4 . There are no valid outcome data to assess whether LP phenotypes respond to ELVR. Only 1 of the 9 LP patients from Chartis analysis received valves in the LP lobe, but the valves had to be removed early due to frequent exacerbations and the lack of subjective improvement. Two LP patients in RUL and LUL were valve targeted in the ipsilateral adjacent LL due to a higher emphysema distribution and lung destruction, and showed comparable results to the $\mathrm{CV}$ - and LF cohort at 3 months. Future studies based on more LP patients treated with valves are urgently required to evaluate whether LP is an appropriate phenotype for ELVR.

Among further possible limitations of the study are the retrospective design and the lack of patient randomization; thus, selection bias cannot be excluded and only data that were recorded in patients' files could be assessed. In most patients, we did not measure all five lung lobes, which would have given us interesting information about the distribution of the Chartis phenotypes in COPD lungs and additional information supporting deductive reasoning on the fissure integrity. We do not know whether the criteria are applicable to Chartis assessments of the mid- dle lobe because too few assessments of the middle lobe were recorded to be included into the study primarily because, due to its small volume, the middle lobe was not targeted for valve therapy. Furthermore, we did not control the Chartis results with other radiological methods, such as a CT scan, which may have given further information about the phenotypes and their distribution in the lung. With respect to reproducibility, we could provide second assessments for some but not all Chartis assessments. All Chartis assessments were done under spontaneous breathing; the cutoff criteria are probably different when the Chartis assessments are performed under ventilation. Applying positive pressure ventilation to Chartis assessment might provide more accurate information about CV because some collaterals might only open under ventilation and remain closed under spontaneous breathing. Therefore, it would be very interesting to compare the outcome data of patients with mismatched Chartis results between spontaneous breathing and positive pressure ventilation.

Nevertheless, our analyses and conclusions are based on a large number of patients and Chartis-measured lobes, and the criteria were effective and reproducible in assessments under spontaneous breathing.

In summary, this study describes the most prevalent Chartis phenotypes in COPD patients: $\mathrm{CV}+, \mathrm{CV}-, \mathrm{LF}$ and LP using Chartis visual patterns and cutoff values for ExpF, Rndx and TVol. While patients with CV-target lobe or LF target lobe and ipsilateral adjacent CV- lobe may successfully be treated with valves, it remains unclear whether patients with LP target lobe improve after valve treatment.

\section{Acknowledgements}

The authors would like to thank Melanie Krueger and Sophie Kästner for excellent assistance in collecting the data, Dr. Konrad Neumann for statistical advice and IB Editorial Services for manuscript editing support.

\section{References}

1 Herth FJ, Eberhardt R, Gompelmann D, Ficker JH, Wagner M, Ek L, Schmidt B, Slebos DJ: Radiological and clinical outcomes of using Chartis $^{\mathrm{TM}}$ to plan endobronchial valve treatment. Eur Respir J 2013;41:302-308.

- 2 Herth FJ, Noppen M, Valipour A, Leroy S, Vergnon JM, Ficker JH, Egan JJ, Gasparini S, Agusti C, Holmes-Higgin D, Ernst A; International VENT Study Group: Efficacy predic- tors of lung volume reduction with Zephyr valves in a European cohort. Eur Respir J 2012;39:1334-1342.

-3 Sciurba FC, Ernst A, Herth FJ, Strange C, Criner GJ, Marquette CH, Kovitz KL, Chiacchierini RP, Goldin J, McLennan G; VENT Study Research Group: A randomized study of endobronchial valves for advanced emphysema. N Engl J Med 2010;363:1233-1244.
-4 Shah PL, Herth FJ: Current status of bronchoscopic lung volume reduction with endobronchial valves. Thorax 2014;69:280-286.

$\checkmark 5$ Valipour A, Herth FJ, Burghuber OC, Criner G, Vergnon JM, Goldin J, Sciurba F, Ernst A; VENT Study Group: Target lobe volume reduction and COPD outcome measures after endobronchial valve therapy. Eur Respir J 2014;43:387-396. 
$\checkmark 6$ Venuta F, Anile M, Diso D, Carillo C, De Giacomo T, D’Andrilli A, Fraioli F, Rendina EA, Coloni GF: Long-term follow-up after bronchoscopic lung volume reduction in patients with emphysema. Eur Respir J 2012;39: 1084-1089.

$>7$ Zoumot Z, LoMauro A, Aliverti A, Nelson C, Ward S, Jordan S, Polkey MI, Shah PL, Hopkinson NS: Lung volume reduction in emphysema improves chest wall asynchrony. Chest 2015;148:185-195.

-8 Bandyopadhyay S, Henne E, Gupta A, Barry R, Snell G, Strange C, Herth FJ: Segmental approach to lung volume reduction therapy for emphysema patients. Respiration 2015;89: 76-81.

$>9$ Cetti EJ, Moore AJ, Geddes DM: Collateral ventilation. Thorax 2006;61:371-373.

10 Gompelmann D, Eberhardt R, Herth FJ: Collateral ventilation. Respiration 2013;85:515520.

11 Higuchi T, Reed A, Oto T, Holsworth L, Ellis S, Bailey MJ, Williams TJ, Snell GI: Relation of interlobar collaterals to radiological heterogeneity in severe emphysema. Thorax 2006;61:409-413.

12 Pu J, Wang Z, Gu S, Fuhrman C, Leader JK, Meng X, Tedrow J, Sciurba FC: Pulmonary fissure integrity and collateral ventilation in COPD patients. PLoS One 2014;9:e96631.

13 Rosenberg DE, Lyons HA: Collateral ventilation in excised human lungs. Respiration 1979;37:125-134.

-14 Terry PB, Traystman RJ, Newball HH, Batra G, Menkes HA: Collateral ventilation in man. N Engl J Med 1978;298:10-15.
15 Bastacky J, Goerke J: Pores of Kohn are filled in normal lungs: low-temperature scanning electron microscopy. J Appl Physiol (1985) 1992;73:88-95.

16 Lambert MW: Accessory bronchiolealveolar communications. J Pathol Bacteriol 1955;70: 311-314.

17 Martin HB: Respiratory bronchioles as the pathway for collateral ventilation. J Appl Physiol 1966;21:1443-1447.

18 Koenigkam-Santos M, Puderbach M, Gompelmann D, Eberhardt R, Herth F, Kauczor HU, Heussel CP: Incomplete fissures in severe emphysematous patients evaluated with MDCT: incidence and interobserver agreement among radiologists and pneumologists. Eur J Radiol 2012;81:4161-4166.

19 Reymond E, Jankowski A, Pison C, Bosson JL, Prieur M, Aniwidyaningsih W, Ferretti GR: Prediction of lobar collateral ventilation in 25 patients with severe emphysema by fissure analysis with CT. AJR Am J Roentgenol 2013; 201:W571-W575.

20 Diso D, Anile M, Carillo C, Ruberto F, Patella M, Russo E, Fraioli F, De Giacomo T, Mantovani S, Rendina E, Venuta F: Correlation between collateral ventilation and interlobar lung fissures. Respiration 2014;88:315-319.

21 Davey C, Zoumot Z, Jordan S, McNulty WH, Carr DH, Hind MD, Hansell DM, Rubens MB, Banya W, Polkey MI, Shah PL, Hopkinson NS: Bronchoscopic lung volume reduction with endobronchial valves for patients with heterogeneous emphysema and intact interlobar fissures (the BeLieVeR-HIFi study): a randomised controlled trial. Lancet 2015;386:1066-1073.
22 Morrell NW, Wignall BK, Biggs T, Seed WA: Collateral ventilation and gas exchange in emphysema. Am J Respir Crit Care Med 1994; 150:635-641.

23 Aljuri N, Freitag L: Validation and pilot clinical study of a new bronchoscopic method to measure collateral ventilation before endobronchial lung volume reduction. J Appl Physiol (1985) 2009;106:774-783.

24 Gompelmann D, Eberhardt R, Michaud G, Ernst A, Herth FJ: Predicting atelectasis by assessment of collateral ventilation prior to endobronchial lung volume reduction: a feasibility study. Respiration 2010;80:419-425.

25 Schuhmann M, Raffy P, Yin Y, Gompelmann D, Oguz I, Eberhardt R, Hornberg D, Heussel C, Wood S, Herth FJ: CT predictors of response to endobronchial valve lung reduction treatment: comparison with Chartis. Am J Respir Crit Care Med 2015;191:767-774.

26 Gompelmann D, Eberhardt R, Slebos DJ, Brown MS, Abtin F, Kim HJ, Holmes-Higgin D, Radhakrishnan S, Herth FJ, Goldin J: Diagnostic performance comparison of the Chartis system and high-resolution computerized tomography fissure analysis for planning endoscopic lung volume reduction. Respirology 2014;19:524-530.

27 Gesierich W, Samitas K, Behr J: Determining collateral ventilation during bronchoscopy: unanswered questions. Thorax 2014;69:289290.

28 Shah PL, Herth FJ: Dynamic expiratory airway collapse and evaluation of collateral ventilation with Chartis. Thorax 2014;69:290291 